Original

\title{
Comparison between a profilometer and a measuring microscope for measurement of enamel erosion
}

\author{
Chanya Chuenarrom and Pojjanut Benjakul \\ Department of Prosthetic Dentistry, Faculty of Dentistry, Prince of Songkla University, Songkhla, Thailand
}

(Received 11 June and accepted 30 October 2008)

\begin{abstract}
The aim of this study was to measure the difference in the erosion depth of enamel measured by profilometry (PM) and a measuring microscope (MM). Sixty enamel specimens were divided into ten groups. Each specimen group was exposed to $50 \mathrm{ml}$ of a carbonated drink with $\mathrm{pH} 2.38$ or orange juice with $\mathrm{pH}$ 3.67 for 15, 30, 60, 120, and 180 minutes. Depths of eroded areas were measured with a profilometer and a measuring microscope. Data of average enamel loss were measured by PM and MM for all erosion times and were scatter plotted on a graph with regression fit. Correlations between the enamel loss measured by PM and MM were analyzed with a paired sample t-test to compare the discriminatory abilities of the two methods of analysis for all erosion times. The regression fit in all study cases showed a high linear relationship $\left(R^{2}=0.90\right)$ between measurements by $P M$ and MM, but in cases where the erosion depth was lower than the depth of focus (DOF) of the MM objective lens, there were weak correlation coefficients $(-\mathbf{0 . 0 0 7}-\mathbf{0 . 3 0 3})$ for comparison between the two measurement methods. (J. Oral Sci. 50, 475-479, 2008)
\end{abstract}

Keywords: enamel; erosion; profilometry; measuring microscope.

\section{Introduction}

Numerous reports on evaluation of enamel erosion have been published since 1892 (1), and research on this subject

Correspondence to Chanya Chuenarrom, Department of Prosthetic Dentistry, Faculty of Dentistry, Prince of Songkla University, Songkhla 90110, Thailand

Tel: +66-74287562

Fax: +66-74429874

E-mail: chanya.ch@psu.ac.th has recently expanded and become more rigorous. In vitro, enamel erosion is measured by various methods including surface microhardness (2), loss of enamel weight (3), SEM or light microscope (4), microradiograph or image analysis (5), electron probe analysis (6), profilometry (7), and light induced fluorescence (8). However, each instrument has limitations. For example, some methods provide only qualitative information, some damage the surface or are very costly. Researchers are thus required to be familiar with the limitation of each methodology in order to obtain accurate and precise results. In a previous study (9), a simple, rapid and non-destructive method was introduced to measure the depth of the channel of a microfluidic chip by using a common microscope based on depth of focus and scales in which fine adjustment could be made. Using this concept, we employed a measuring microscope to measure the enamel erosion depth.

A three-direction measurement microscope is a noncontact optical microscope using light rays. It provides repeatable accuracy using automatic measurement in three axes ( $\mathrm{x}, \mathrm{y}$, and $\mathrm{z})$. The depth of the specimen surface in the $\mathrm{z}$-axis was measured using the focusing method, allowing the measurement of enamel erosion. A few studies have used this microscope for measuring dental material dimensions (10), but there have not been any previous studies which employed a measuring microscope to evaluate enamel erosion. The aim of this study was to measure the difference in enamel erosion depths at different exposure times measured by a measuring microscope and profilometry, which was used as the gold standard (11).

\section{Materials and Methods}

Ten caries-free human third molars were used for the study. Teeth were extracted from patients, aged 25 to 45 years old, at the Dental Hospital, Faculty of Dentistry, Prince of Songkla University, Songkhla, Thailand. Longitudinal 
enamel sections $(n=60)$ were prepared from 10 molars using a diamond saw (Isomet 4000, Buehler, IL, USA) under water irrigation. From each tooth, six sections were cut accordingly: one section from the distal, mesial and two sections each from both the lingual and buccal. Each specimen was embedded in acrylic resin and the outer enamel surface was ground flat using 320, 600 and 1200 grit silicon carbide paper (Wirtz Buehler, Düsseldorf, Germany). Specimens were assigned to one of the six groups. The results included five groups each for five different exposure times in orange juice (Tipco, Batch no.22:50A27, Tipco F\&B Co., Ltd., Bangkok, Thailand) with $\mathrm{pH} 3.67$ and another five groups each for five different exposure times in a carbonated drink (Coke, batch no. F42S1018, Thai Namthip Co. Ltd., Bangkok, Thailand) with $\mathrm{pH}$ 2.38. The $\mathrm{pH}$ values were measured by a $\mathrm{pH}$ meter (Precisa, pH900, Precisa Gravimetrics AG, Dietikon, Switzerland). The enamel specimens were covered with nail varnish leaving an area of approximately $1.5 \times 1.5 \mathrm{~mm}^{2}$ in the center area for exposure to the drink. This procedure ensured comparison between the eroded and uneroded area; the uneroded area was used as a reference for the erosion depth.

Ten specimens each were exposed to $50 \mathrm{ml}$ of carbonated drink or orange juice for 15, 30, 60, 120, and $180 \mathrm{~min}$. The specimen beakers were held and shaken in a continuously vibrating water bath (Memmert, WNB22, Memmert $\mathrm{GmbH}$, Büchenbach, Germany) at $37^{\circ} \mathrm{C}$ for an assigned immersion time. Then, specimens were rinsed in tap water and dried naturally at room temperature for $15 \mathrm{~min}$. Nail enamel remover was applied over nail varnish that covered the uneroded area until clean. A stereomicroscope (Nikon,
SMZ1500, Nikon Corporation, Kanagawa, Japan) with a $\times 112.5$ magnification was used to confirm that the nail varnish was completely removed from the enamel surface. Height levels of eroded and uneroded areas were measured with a profilometer and a measuring microscope.

After erosion, profilometry was performed using a contact profilometer (Surfcorder SE2300, Kosaka Laboratory, Tokyo, Japan) with a 5 - $\mu$ m radius diamond stylus tip under a 4-mN load. The stylus traveled across the eroded and uneroded areas at a velocity of $0.5 \mathrm{~mm} / \mathrm{min}$ perpendicularly to the specimen surface for a tracing length of $2.5 \mathrm{~mm}$. The vertical and horizontal magnification profiles were set at $\times 1,000$ and $\times 50$, respectively. The erosion depth is defined as the distance between the uneroded surface and the eroded bottom of the profile (Fig. 1), and erosion depth was measured for every 100 $\mu \mathrm{m}$ of tracing length on the eroded profile. The data was then averaged. Each specimen was traced three times for definition as the mean erosion depth.

Evaluation with the measuring microscope (Nikon, MM400, Nikon Corporation, Kanagawa, Japan) was done with a 500x magnification along the $\mathrm{x}, \mathrm{y}$, and $\mathrm{z}$ axes. A specimen block was mounted on a plane-leveling stage to ensure that the specimen surface under inspection was perfectly flat and then placed on the microscope $x-y$ stage. For each measurement, two positions (R1 and R2) on the uneroded area were specified to be the reference height (Fig. 2). Depths of eroded areas were focused for every $100 \mu \mathrm{m}$ along a distance of about $1.5 \mathrm{~mm}$ on the $\mathrm{x}$-axis, and the data were averaged. The average value of three measurements was calculated for each specimen.

Data of average enamel loss measured by MM and PM
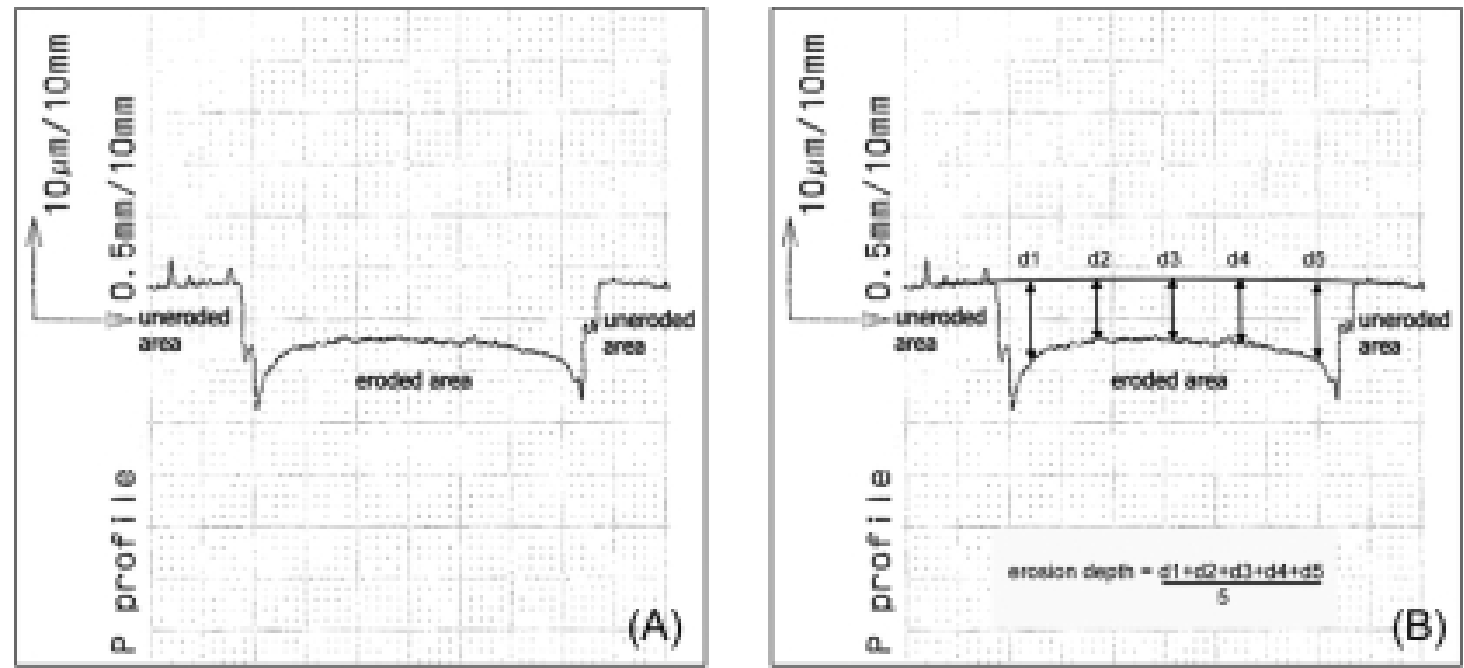

Fig. 1 (A) Profile for the measurement of erosion depth by a profilometer. (B) Five positions on the profile were measured to find the depth between the uneroded and eroded line to calculate the average erosion depth. 
on overall erosion times were scatter plotted on the graph with regression fit. For variable groups (beverage with exposure time), the paired $t$-test, with a level of confidence of $95 \%$, was used to compare the results between PM and MM. Pearson's correlation coefficient was used to determine the relationship between the two methods.

\section{Results}

The scatter plot in Fig. 3 shows a highly linear relationship $\left(\mathrm{R}^{2}=0.90\right)$ between measurements by PM and $\mathrm{MM}$ for all cases. The range, mean, standard deviation and paired samples $t$-test were used to compare the erosive measuring abilities of the two methods for enamel in orange juice and Coke at different soaking times as shown in Table 1 and Fig. 4. Correlation coefficients and statistically significant correlations between PM and MM are presented in Table 2.

Orange juice showed lower erosive potential than Coke. Coke took 180 minutes to erode $8.29 \mu \mathrm{m}$ of enamel, whereas for the same time period, orange juice eroded only $1.1 \mu \mathrm{m}$ of enamel when measured with PM. Data from Table 2 showed a significant correlation between the two methods when enamel loss was approximately $1 \mu \mathrm{m}$. However, there was a low discriminatory ability for both MM and PM methods for measuring erosion in orange juice because enamel loss was less than $1 \mu \mathrm{m}$.

Table 1 Distribution range and mean (S.D.) enamel erosive loss $(\mu \mathrm{m})$ in orange juice and Coke at different exposure times by a profilometer (PM) and a measuring microscope (MM), and results of paired samples $t$-test to determine their relative effectiveness

\begin{tabular}{|c|c|c|c|c|c|}
\hline \multirow{2}{*}{ Time $(\min )$} & \multicolumn{2}{|c|}{ Min to max (range) } & \multicolumn{2}{|c|}{ Mean (S.D.) } & \multirow[b]{2}{*}{$P$} \\
\hline & PM & MM & PM & MM & \\
\hline \multicolumn{6}{|l|}{ Orange iuice } \\
\hline 15 & $\mathrm{~N} \Lambda$ & -0.4 to $1.1(1.5)$ & $\mathrm{N} \Lambda$ & $0.25(0.42)$ & $\mathrm{N} \Lambda$ \\
\hline 30 & 0.5 to $1.2(0.7)$ & -0.1 to $1.5(1.6)$ & $0.80(0.19)$ & $0.56(0.44)$ & $0.044^{*}$ \\
\hline 60 & 0.5 to $1.0(0.5)$ & -0.3 to $2.2(2.5)$ & $0.75(0.14)$ & $0.85(0.67)$ & 0.548 \\
\hline 120 & 0.1 to $1.3(1.2)$ & -0.4 to $1.2(1.6)$ & $0.62(0.28)$ & $0.32(0.48)$ & $0.015^{*}$ \\
\hline 180 & $0.2101 .6(1.4)$ & -1.0 to $3.0(4.0)$ & $1.1(0.49)$ & $0.68(0.79)$ & $0.006^{*}$ \\
\hline \multicolumn{6}{|l|}{ Coke } \\
\hline 15 & 0.5 to $1.1(0.6)$ & -1.0 to $4.3(5.3)$ & $0.71(0.17)$ & $0.18(1.16)$ & 0.072 \\
\hline 30 & 0.6 to $2.7(2.1)$ & -0.4 to $3.1(3.5)$ & $1.49(0.82)$ & $1.33(0.97)$ & 0.350 \\
\hline 60 & 1.1 to $5.8(4.7)$ & 0.8 to $4.9(4.1)$ & $2.73(1.23)$ & $3.02(1.12)$ & 0.139 \\
\hline 120 & 3.9 to $10.9(7.0)$ & 3.5 to $7.6(4.1)$ & $6.73(1.88)$ & $5.97(1.29)$ & 0.051 \\
\hline 180 & 5.9 to $13.7(7.8)$ & 5.1 to $11.3(6.2)$ & $8.29(1.93)$ & $8.11(1.87)$ & 0.488 \\
\hline
\end{tabular}

Table 2 Correlations between a profilometer (PM) and a measuring microscope (MM) in determining enamel erosive loss $(\mu \mathrm{m})$ in orange juice and Coke at different exposure times

\begin{tabular}{lccccc}
\hline & \multicolumn{5}{c}{ Exposure time (min) } \\
\cline { 2 - 6 } & 15 & 30 & 60 & 120 & 180 \\
\hline Orange juice & $\mathrm{N} A$ & -0.007 & -0.034 & 0.303 & $0.681^{*}$ \\
Coke & 0.016 & $0.697^{*}$ & $0.778^{*}$ & $0.644^{*}$ & $0.833^{*}$ \\
\hline * represents correlation significant at $P<0.05$, NA & $=$ Not applicable
\end{tabular}

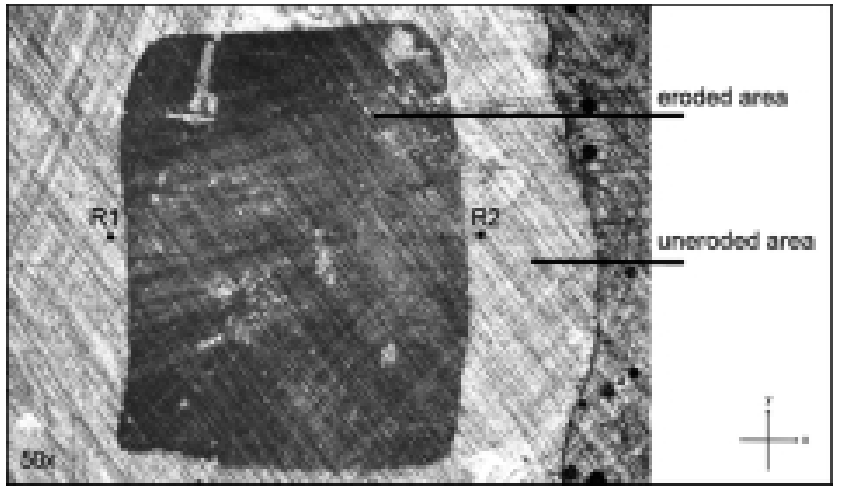

Fig. 2 Image of enamel surface for the measurement of erosion depth by measurement microscope.

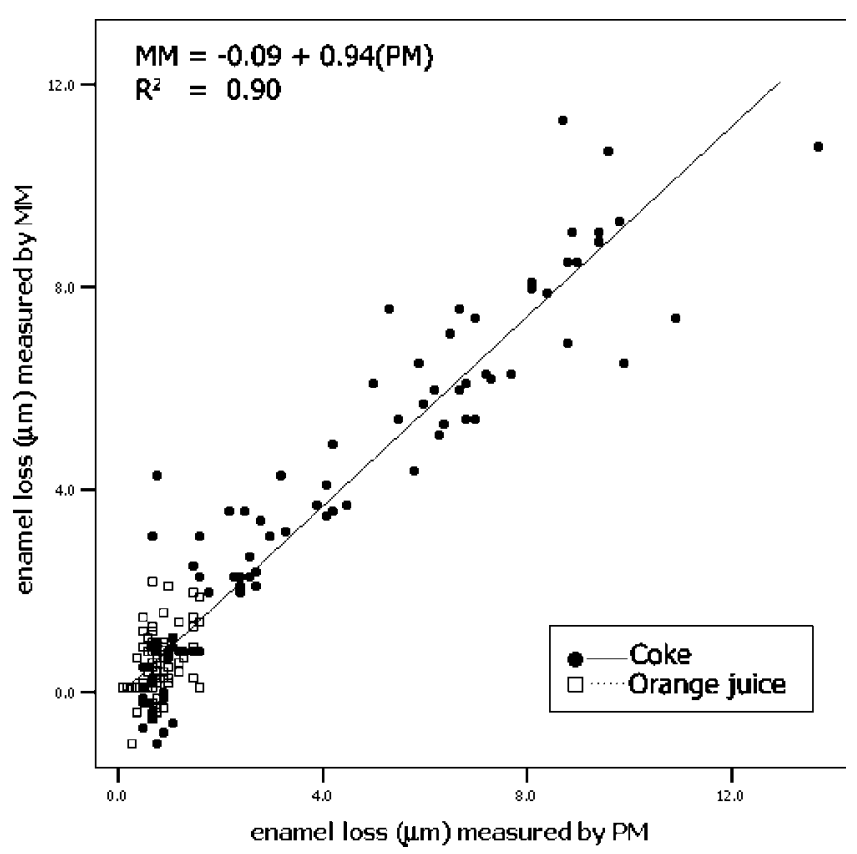

Fig. 3 Correlation for erosion loss $(\mu \mathrm{m})$ in orange juice and Coke, as measured by PM and MM.

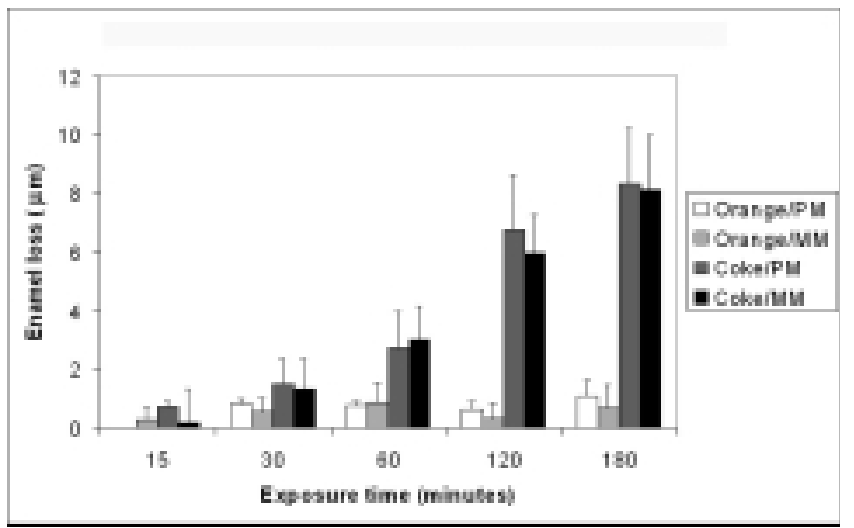

Fig. 4 Enamel loss in orange juice and Coke at different exposure times, as measured by PM and MM. 


\section{Discussion}

With regard to the comparison between PM and MM at different erosive levels, carbonated drink and orange juice were chosen because they have different erosive potential $(12,13)$. In this study, the erosive potential of orange juice and Coke on enamel was similar to those reported in a previous study $(13,14)$. The erosive potential corresponded well to the $\mathrm{pH}$ of the beverage, thus Coke ( $\mathrm{pH} 2.38)$ had a clearly higher erosive potential than orange juice $(\mathrm{pH}$ 3.67).

Based on the scatter plots of overall data and coefficients of determination $\left(\mathrm{R}^{2}\right)$ for the influence of beverages on enamel loss as measured by PM and MM, the $\mathrm{R}^{2}$ was as high as 0.90 and the regression line nearly passed through the intersection point of the figure. These results indicate that the two methods had very good agreement. However, the overall $\mathrm{R}^{2}$ was not applicable for each experimental group. Therefore, in the present study, Pearson's correlation coefficient and $t$-test statistical approaches were proposed to determine the concordance between PM and MM for each individual experimental group. Correlation coefficients measure the strength of a relationship between two variables, while the $t$-test determines whether there is a significant difference between the mean values of two groups (15).

In Table 1, the $t$-test for paired samples in the Coke group revealed that there was no significant difference between the two methods, whereas for the correlation test, Table 2 showed a high correlation $(0.644-0.833)$ between PM and MM for erosive depth when enamel was immersed in orange juice for more than 180 min or in Coke for more than $30 \mathrm{~min}$, where the average enamel loss was more than $1 \mu \mathrm{m}$. Conversely, when the average enamel loss was less than $1 \mu \mathrm{m}$, the correlation coefficient between PM and MM was weak. If the correlation between two measurement methods is weak and there is significant difference between the results obtained with the two methods, the two methods are not interchangeable (16). Thus, the difference in the results when the erosion depth is less than $1 \mu \mathrm{m}$ is considered to be a limitation of the two measuring instruments.

Contact stylus profilometers are widely used for measurement of the contours of the enamel surface because they give highly repeatable and direct profiles of high resolution $(17,18)$. However, a diamond stylus can scratch the enamel surface or a delicate surface such as dentin. Therefore, this method may not be appropriate for some specimens. Furthermore, the discrimination ability of PM varies based on its magnification. In this study, a vertical magnification of $\times 1,000$ could not discriminate differences in height between uneroded and eroded profiles of enamel exposed for 15 min in orange juice. In practice, this effect may be overcome by using a higher vertical magnification but it may not appropriate for measurements of various depth levels such as those investigated in this study, because measurement of high erosion produced an overprofile and the results could not be reported.

For the measuring microscope used in this study, the $\times 50$ magnification of the objective lens had a depth of focus (DOF) of $1.4 \mu \mathrm{m}$. The DOF is the distance from the nearest image plane in focus to that of the farthest plane which is also simultaneously in focus, and varies with numerical aperture and magnification of the objective. The enamel surface was then placed within this DOF range. The surface can be viewed with no loss of sharpness. Data of enamel loss of less than $1 \mu \mathrm{m}$ showed a great standard deviation. In addition, there were numerous positions on the eroded enamel with a focused depth in the z-axis that was higher than the depth of the uneroded area (the negative value of enamel loss in Table 1). This information indicated that precision depends on DOF and focusing to obtain a sharp image. In theory, the error of measurement could not be greater than the DOF (9). In Table 1, enamel immersed in orange juice at 15 to $180 \mathrm{~min}$ lost less than $1 \mu \mathrm{m}$ of tissue. Correlation indicated a low relation between the two methods. Although, measuring with a measuring microscope is a simple, rapid and non-destructive method, it may not be suitable for measuring enamel with very low erosion or initial erosion because the measurement accuracy is based upon the DOF of the objective lens. Thus, for decreasing erroneous measurement, an objective lens with a DOF of less than the erosive depth should be used.

\section{Acknowledgments}

This study was supported by The Princess Mother's 100th Year Honoured Fund, from the Faculty of Dentistry, Prince of Songkla University, Songkhla, Thailand. The authors would like to thank Mr. Mitchell Allan Bruce Atkins for editing the manuscript.

\section{References}

1. Bartlett DW (1997) The causes of dental erosion. Oral Dis 3, 209-211

2. Lupi-Pegurier L, Muller M, Leforestier E, Bertrand MF, Bolla M (2003) In vitro action of Bordeaux red wine on the microhardness of human dental enamel. Arch Oral Biol 48, 141-145

3. Jain P, Nihill P, Sobkowski J, Agustin MZ (2007) Commercial soft drinks: $\mathrm{pH}$ and in vitro dissolution of enamel. Gen Dent 55, 150-154

4. Owens BM, Kitchens M (2007) The erosive potential of soft drinks on enamel surface substrate: an in vitro 
scanning electron microscopy investigation. J Contemp Dent Pract 8, 11-20

5. Hall AF, Buchanan CA, Millett DT, Creanor SL, Strang R, Foye RH (1999) The effect of saliva on enamel and dentine erosion. J Dent 27, 333-339

6. Willershausen B, Schulz-Dobrick B (2004) In vitro study on dental erosion provoked by various beverages using electron probe microanalysis. Eur J Med Res 9, 432-438

7. Phelan J, Rees J (2003) The erosive potential of some herbal teas. J Dent 31, 241-246

8. Pretty IA, Edgar WM, Higham SM (2004) The validation of quantitative light-induced fluorescence to quantify acid erosion of human enamel. Arch Oral Biol 49, 285-294

9. Liu J, Tian C, Wang Z, Lin J-M (2007) Measurement of channel depth by using a general microscope based on depth of focus. Eurasian J Anal Chem 2, 12-20

10. Thielke S, Serrano JG, Lepe X (1998) A method for true coordinate three-dimensional measurement of casts using a measuring microscope. J Prosthet Dent 80, 506-510

11. Hall AF, Sadler JP, Strang R, de Josselin de Jong E, Foye RH, Creanor SL (1997) Application of transverse microradiography for measurement of mineral loss by acid erosion. Adv Dent Res 11,
420-425

12. Jensdottir T, Bardow A, Holbrook P (2005) Properties and modification of soft drinks in relation to their erosive potential in vitro. J Dent 33, 569575

13. Jensdottir T, Holbrook P, Nauntofte B, Buchwald C, Bardow A (2006) Immediate erosive potential of cola drinks and orange juices. J Dent Res 85, 226230

14. Ehlen LA, Marshall TA, Qian F, Wefel JS, Warren JJ (2008) Acidic beverages increase the risk of in vitro tooth erosion. Nutr Res 28, 299-303

15. Amenábar JM, Martins GB, Cherubini K, Figueiredo MA (2006) Comparison between semi-automated segmentation and manual point-counting methods for quantitative analysis of histological sections. J Oral Sci 48, 139-143

16. Bland JM, Altman DG (1999) Measuring agreement in method comparison studies. Stat Methods Med Res 8,135-160

17. Frühauf J (1998) Problems of contour measuring on microstructures using a surface profiler. Meas Sci Technol 9, 293-296

18. Whitehead SA, Shearer AC, Watts DC, Wilson NH (1999) Comparison of two stylus methods for measuring surface texture. Dent Mater 15, 79-86 